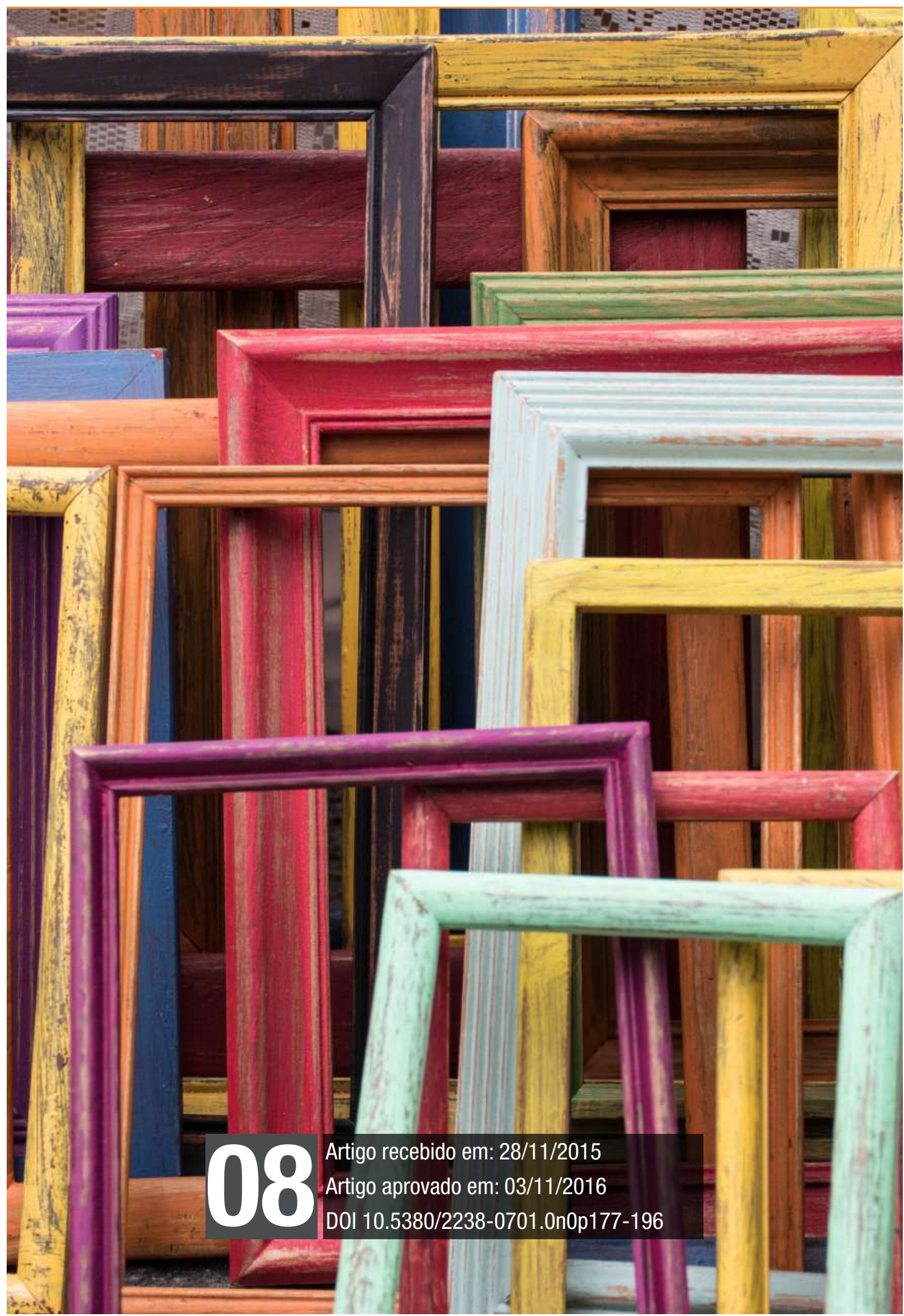


Discurso. Poder. Tablets. 


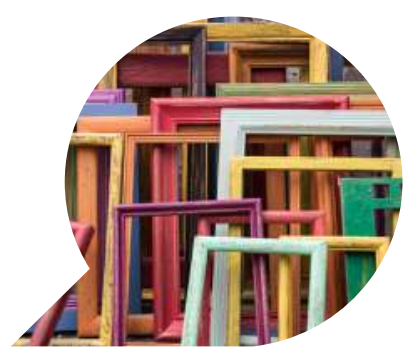

\section{O poder de fazer mais! Uma análise da formação dos tablets enquanto um objeto discursivo}

The power to do more! An analysis of the formation of the
tablets while a discursive object

¡El poder de hacer más! Un análisis de la formación de los tabletas mientras que un objeto discursivo

CÉDRICK CUNHA GOMES DA SILVA ${ }^{1}$

FERNANDO GOMES DE PAIVA JÚNIOR ${ }^{2}$

SÉRGIO CARVALHO BENÍCIO DE MELLO ${ }^{3}$

Resumo: A invenção dos tablets representou uma ruptura no mercado de tecnologias móveis. Porém, a hegemonia dos discursos em torno das grandes marcas tem produzido relações de desigualdade e marginalização daqueles considerados obsoletos frente a esse progresso tecnológico. Neste sentido, neste estudo buscamos por meio de uma abordagem crítica de Análise Retórica compreender

\footnotetext{
${ }^{1}$ Doutorado em Administração (UFPE), mestrado em Administração (UFPE), bacharelado em Administração (UFPE). Email: cedrickgomes@gmail.com

${ }^{2}$ Doutorado em Administração (UFMG), mestrado em Administração (Universidad de Deusto, UD, Espanha), graduação em Administração (UFPE). É professor e pesquisador da Universidade Federal de Pernambuco. Email: fernando.paivajr@gmail.com

${ }^{3}$ Doutorado em Business Studies (City University London), mestrado em Administração (UFPB), graduado em filosofia (UFPE), graduado em Administração (UNICAP). É professor e pesquisador da Universidade Federal de Pernambuco. Email: sergio.benicio@gmail.com
} 
como argumentos persuasivos influenciados por relações de poder/discurso são desenvolvidos nos enunciados publicitários de sujeitos presentes no mercado de tablets. Algumas das conclusões apontam como uma gama de conceitos, por exemplo, liberdade e eficiência, são articulados na formação dos tablets enquanto objeto discursivo.

Palavras-chave: Discurso; Poder; Tablets.

Abstract: The invention of tablets represented a break in the mobile technology market. But the hegemony of discourses around the big brands has produced unequal relations and marginalisation of those considered obsolete front of this technological progress. In this sense, this study aims, through a critical approach to Rhetorical Analysis, to comprehend how persuasive arguments influenced by relations of power/discourse are developed in the advertising statements of subjects present in the tablet market. Some of the conclusions point that a range of concepts, for example, freedom and efficiency, are articulated in the formation of the tablets while a discursive object.

Keywords: Discourse; Power; Tablets.

Resumen: La invención de tabletas representó una ruptura en el mercado de la tecnología móvil. Pero la hegemonía de los discursos en torno a las grandes marcas ha producido relaciones desiguales $y$ la marginación de los que se consideran obsoletos frente de este progreso tecnológico. En este sentido, este estudio tiene como objetivo, a través de un enfoque crítico de análisis retórico, para comprender cómo los argumentos persuasivo influenciados por las relaciones de poder/discurso se desarrollan en los estados de publicidad de los sujetos presentes en el mercado de las tabletas. Algunas de las conclusiones apuntan que una serie de conceptos, por ejemplo, la libertad y la eficiencia, se articulan en la formación de las tabletas mientras que un objeto discursivo.

Palabras clave: Discurso; Poder; Tabletas. 


\section{Introdução a um novo discurso}

Ao longo dos primeiros anos da Revolução Industrial e após essa, o ritmo de desenvolvimento e consumo dos mais variados tipos de tecnologias apresentaram maior intensidade, porém em ritmo de desenvolvimento ainda lento. Atualmente, contudo, o intervalo de lançamento de uma tecnologia para outra que irá substituí-la ou incrementá-la passou de anos para meses, ou mesmo semanas. A televisão, por exemplo, que modificou diversas formas de relações e mediações na vida dos indivíduos, levou anos para ser modificada. Porém, nesse princípio de século XXI, temos cada vez mais incrementações nesse aparato, como tecnologias Widescreen, Wifi e 3D.

Esse artigo, no entanto, não se propôs a analisar esse aparato tecnológico, mas um que tem apresentado grande destaque nas mídias de massa e nas mídias sociais. Com intenso número de propagandas publicitárias e desenvolvimentos de diversos modelos, os tablets têm atraído a atenção de múltiplos agentes e instituições políticas, econômicas, sociais e até mesmo religiosas. Surgindo inicialmente com o Kindle da empresa Amazon, os tablets ganharam destaque no mercado de tecnologias móveis com o primeiro lançamento do iPad da empresa Apple. Desde então, essa tecnologia tem sido inserida nas mais diversas esferas e práticas da sociedade contemporânea, criando novas identidades, costumes, regulações e até mesmo novos modelos produtivos.

Recentemente, o governo brasileiro realizou vários acordos com empresas responsáveis pela produção desses dispositivos buscando produzi-los em território nacional e popularizá-los localmente. Para tal, o governo também desenvolveu políticas de isenção de impostos. A presidente da República, Dilma Rousseff, sancionou em 11 de outubro de 2011 a lei que isenta o pagamento de PIS e Cofins na produção de tablets no país (LIMA, 2011). De cada 3 usuários de tablets na América Latina, mais de um é brasileiro segundo relatório realizado pela eMarketers (2015). Em 2015, o país ultrapassará o Reino Unido, tornando-se o quarto maior consumidor de tablets no mundo, com 34,7 milhões de usuários.

Diversas empresas e modelos inseridos nesse mercado vêm apresentando intenso crescimento. Podemos identificar desde grandes marcas como o iPad, da Apple, o Xoom, da Motorola e o Galaxy, da Samsung, até os produtos de marcas menos populares como o Iconia, da Acer e o Elepad, da Asus. Além desses, podemos ainda identificar a fabricação de 
outros modelos que podem ser conhecidos popularmente como "clones" ou "piratas" das grandes marcas, como é o caso do aPad e o ePad.

A mídia apresenta grande impacto sobre os modos de agir e pensar nossa realidade, influenciando indiscutivelmente nas construções de identidades e subjetividades, como apresentado por Barbero (2003). Igualmente, o discurso publicitário impõe diversos elementos simbólicos como valores e mitos, fazendo uso da própria língua como veículo. O imperativo publicitário utiliza-se de aspectos tanto racionais do objeto (por exemplo, suas características técnicas) quanto pelo desenvolvimento e experimentação de desejo por meio de elementos linguísticos e semânticos (CARVALHO, 1996).

Não se pretende aqui analisar aspectos relacionados ao consumo físico ou material desses tablets, mas sim analisar como são construídas relações de poder e discurso por meio dos slogans publicitários desenvolvidos pelas organizações produtoras desses dispositivos. Para tal, apresentamos nas próximas seções um debate em torno das influências do discurso nas relações de poder, assim como as influências das relações de poder na construção e reprodução de discursos. Em seguida, apresentamos os caminhos metodológicos utilizados para a realização desse estudo e, por fim, antes das considerações finais, será apresentada a análise dos discursos publicitários de algumas empresas produtoras do artefato tecnológico que nos propomos a analisar.

\section{Primeiro o discurso...}

Nossa compreensão de discurso é profundamente influenciada pelos trabalhos de Foucault (1979) e de Laclau e Mouffe (2001). No primeiro, temos o entendimento de discurso ou formação discursiva como um corpo de conhecimento que sistematicamente forma o objeto de que se fala. Para Laclau e Mouffe (2001), o discurso deve ser entendido como uma totalidade estruturada resultante de uma prática articulatória. A articulação não deve ser pensada apenas em termos ideológicos ou culturais, mas também em torno de práticas e instituições materiais.

Os discursos são vistos dentro de domínio social específico, ou seja, "um discurso é entendido como a fixação de significado dentro de um domínio particular” (JORGENSEN; PHILLIPS, 2002, p. 26). Dessa forma, o significado social só tem sentido por meio do discurso. Esse não serve apenas como uma descrição do mundo social, mas constitui e dá sentido ao mesmo. 
Os discursos governam as formas com que as coisas podem ser pensadas e faladas. De acordo com Hall (2001), ele influencia como as ideias são colocadas em prática. Contribuindo na construção da subjetividade dos indivíduos, assim como suas experiências cotidianas. Nossas práticas e interações diárias são efeitos materiais do discurso sobre nossa capacidade de pensar e agir. Discurso é prática, assim, falar é agir. Ao agir estamos reproduzindo discursos que constituem nossa realidade e nosso ser. Da mesma forma, estamos contribuindo para seu fortalecimento.

Discursos constituem certos tipos de categorias sociais. Elas podem ser definidas como conceitos, objetos e posições de sujeitos (HARDY; PHILLIPS, 2004). Os conceitos se referem às "ideias, categorias, relacionamentos e teorias pelas quais entendemos o mundo" (HARDY; PHILIPS, 1999, p. 3). Apesar dos conceitos residirem no âmbito das ideias, eles produzem efeitos materiais, impactando em nossas práticas e ações sociais.

Um objeto, por sua vez, se constitui quando um ou mais conceitos são utilizados para dar sentido a uma realidade material. Laclau e Mouffe (2001) não negam a existência das coisas além do discurso, porém o entendimento e conhecimento que temos delas só é possível por meio desse.

Por último, posição de sujeito refere-se à localização de um indivíduo em espaços sociais e em uma estrutura discursiva (LACLAU; MOUFFE, 2001). Os discursos sempre designam posições para os indivíduos ocuparem como sujeitos. Para Laclau e Mouffe (2001), o sujeito é sempre sobredeterminado porque os discursos são sempre contingentes, não apresentando uma lógica objetiva que direcione a uma única posição de sujeito.

Trivinho (2007) apresenta em sua obra o conceito de dromoapto referindo-se a uma elite de indivíduos que possuem condições cognitivas e financeiras para acompanhar com velocidade as transformações tecnológicas, realizando inclusão permanente na cibercultura. Dromo é um prefixo grego que significa agilidade, propensão. $\mathrm{O}$ inapto pode ser compreendido como o oposto do dromoapto. Podemos comparar o conceito de dromoinapto (que existe como uma ideia) com aqueles indivíduos que são determinados como dromoinaptos por meio de práticas discursivas associadas aos processos sociais que levam a tal condição ou posição. Esses indivíduos não são dromoinaptos por essência, porém esse conceito e o discurso produzem práticas discursivas que permitem que eles sejam rotulados como tal. Sendo assim, os efeitos do conceito de dromoinapto são materializados. 
O discurso contribui para a construção de realidades sociais à medida que constitui objetos, formas de conhecimento, relações sociais, conceitos e posições de sujeitos. Por meio da criação de sentido dessas categorias básicas desenvolvemos compreensão de mundo e agimos de acordo com essa compreensão. Nossas práticas cotidianas são reflexos dos significados e sentidos criados pelos discursos e pelas posições de sujeitos que assumimos ininterruptamente.

\section{... depois o Poder e vice-versa}

Discurso e Poder são mutualmente constitutivos à medida que os discursos moldam as relações de poder e estas influenciam o discurso de modo específico ao longo de um período de tempo. Para Foucault (1998), qualquer sistema de conhecimento constitui um sistema de poder. Poder e conhecimento são integrados no discurso, assim, discurso e poder são inseparáveis. Pelo fato de alguns sujeitos possuírem acesso a uma maior gama de poderes, esses possuirão maior influência e competência para produzir textos que irão afetar de forma mais direta certos discursos. Da mesma forma, aqueles que detêm maior conhecimento sobre determinado conteúdo terão mais poder de influência sobre o discurso específico ao mesmo.

Poder na concepção de Foucault (1998) não é algo conectado ou pertencente simplesmente a um sujeito, mas, sim, representa uma rede complexa de relações determinadas pelos sistemas de conhecimento. Sistemas esses constituídos pelos discursos. Tal poder é exercido nas inúmeras posições, em um jogo de relações desiguais. Dentro de uma rede discursiva poderemos identificar diferentes níveis de poder.

Sujeitos podem ser considerados poderosos apenas em contextos discursivos particulares. $\mathrm{O}$ poder está relacionado à capacidade de se fixar, ao menos temporariamente, categorias de existência, representadas por meio de práticas e formas discursivas (FOUCAULT, 1998; LACLAU; MOUFFE, 2001; HARDY; PHILLIPS, 2004; CLEGG, 1989). Na concepção de Laclau e Mouffe (2001), essas seriam condições de possibilidades que influenciam e determinam quais práticas discursivas são possíveis em determinado momento e contexto. Essas condições de possibilidade determinam porque um enunciado particular aparece ou é utilizado em vez de tantos outros.

A abordagem dada por Laclau e Mouffe (2001) ao discurso contribui para um avanço nas concepções de Foucault. Na visão dos autores, 
os indivíduos fazem parte de múltiplos discursos em meio a tensões discursivas permanentes que produzem espaços de disputa por uma hegemonia. Essa hegemonia seria uma posição privilegiada ocupada por determinado discurso em um contexto específico. Essas disputas representam disputas de poder e produzem movimentos ou deslocamentos dentro das redes discursivas que resultam em mudanças nos discursos ao longo do tempo. Essas práticas discursivas de poder/conhecimento também podem ser pensadas como estratégias de controle em contextos históricos e institucionais.

O exercício de poder ocorre pela articulação de sentidos e significados que legitimam determinada visão de mundo como algo essencial e inevitável. A fixação de sentidos intersubjetivos contribui para a criação de uma realidade particular compartilhada e reproduzida por meio das ações de outros sujeitos (HARDY; PHILLIPS, 2004). Quem possuir o poder de fixar certo discurso converge dessa forma às ações e preferências de outros para o alcance de seus objetivos e interesses. Essa prática pode ser comumente observada em ações publicitárias que buscam manipular sua audiência de forma a moldar suas ações e alcançar seus objetivos organizacionais, como, por exemplo, aumento nas vendas.

A Figura 1 ilustra como se dá o processo dinâmico em que se mantendo os significados particulares associados aos conceitos, objetos e posições de sujeitos, o discurso influencia e molda as relações de poder que por sua vez determinam e direcionam as condições de possibilidades das práticas discursivas (HARDY; PHILLIPS, 2004).

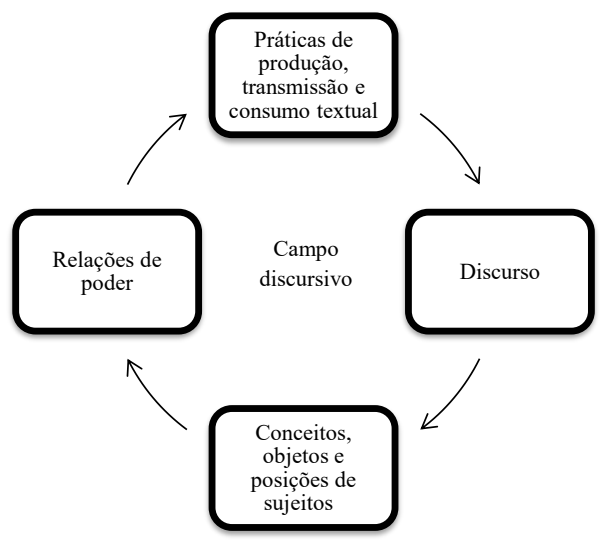

Figura 1: Relacionamento entre Discurso e Poder (HARDY; PHILLIPS, 2004). 
Podemos observar, por meio da Figura 1, como ocorre o processo de influência do discurso nas relações de poder, porém não é possível vislumbrar como as práticas discursivas de produção, transmissão e consumo influenciam e afetam o discurso ao longo do tempo. $\mathrm{Na} \mathrm{Fi-}$ gura 2 temos um processo em que as práticas discursivas podem gerar mudanças no próprio discurso com o tempo.

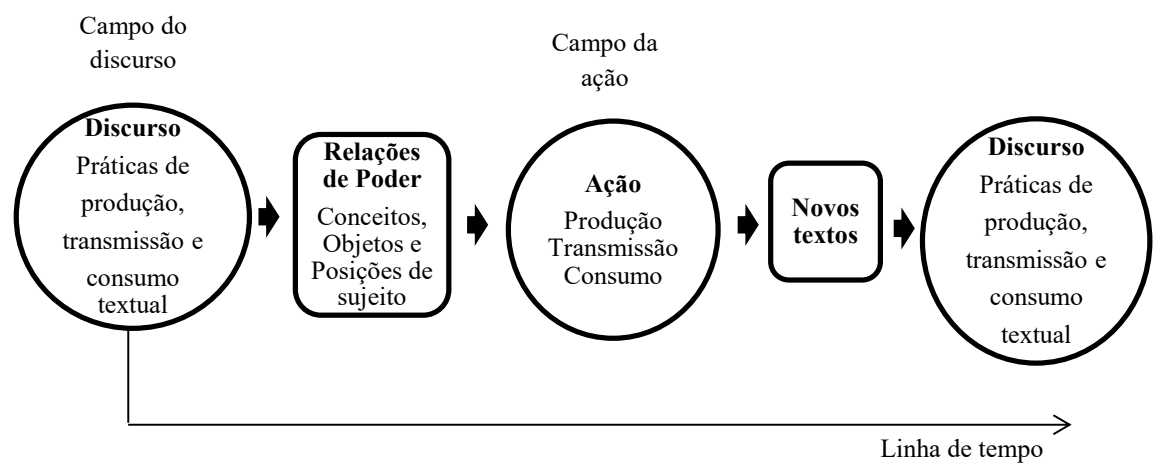

Figura 2: Relacionamento entre Poder e Discurso

(HARDY; PHILLIPS, 2004).

As relações de poder, segundo Hardy e Phillips (2004, p. 305), “afetam a produção de textos e moldam o discurso através do tempo". A Figura 2 apresenta uma evolução com relação a Figura 1 na medida que na primeira parte temos a influência entre discurso e poder e na segunda, temos a influência das relações de poder sobre os discursos. Dessa forma, podemos concluir que discurso e poder são mutualmente constitutivos. Em certo contexto ou momento podemos analisar a relação discurso-poder, enquanto em outro, a relação poder-discurso.

\section{Processos de Comunicação: codificação, decodificação e reprodução}

As pesquisas tradicionais em comunicação de massa concebiam o processo comunicativo como um modelo linear, onde faziam parte do mesmo, três elementos básicos: o emissor, a mensagem e o receptor. Ao longo do tempo, esse modelo foi bastante criticado por sua concentração apenas no nível de troca de mensagem e pela ausência de uma concepção mais estruturada e ampla dos diferentes momentos desse processo enquanto uma complexa estrutura de relações de poder. Esse modelo se apresenta de forma bastante reducionista, não considerando 
as diversas nuances e contextualizações do processo de comunicação social, político, cultural, econômica e ideológica (HALL, 2003). Dessa forma, esse modelo não se enquadra no paradigma da complexidade em que a sociedade pós-moderna está envolvida e na qual os processos discursivos analisados nesse artigo estão inseridos.

Com os trabalhos desenvolvidos inicialmente por Stuart Hall, tornou-se mais útil considerar o processo de comunicação como uma estrutura mais complexa, produzida e sustentada por meio de processos distintos como produção, circulação, distribuição/consumo e reprodução, porém, todos esses articulados e interligados. Tal modelo nos traz a noção de momentos dentro do circuito, ou seja, um momento de produção, um momento em que se tem uma distribuição da mensagem ou discurso produzido, um momento de consumo desse pelo receptor, onde serão consideradas as estruturas que compõem esse momento de recepção, e, por último, considera-se um momento de reprodução em que se dará uma continuidade ao processo, iniciando outro. O próprio receptor assume então uma posição de produção, ao passo que esse irá decodificar a mensagem inicial e codificar (igualmente, parcialmente ou diferentemente) a mesma, para distribuir em outro momento e em outros contextos (HALL, 1999; HALL, 2003).

Tomando emprestado esse modelo de comunicação, surge a possibilidade de inserção de várias das categorias e elementos utilizados por Hardy e Phillips (2004), bem como Laclau e Mouffe (2001). Podemos notar que em cada etapa desse complexo circuito é possível identificar conceitos, articulações, posições de sujeito, objetos e discursos hegemônicos. De acordo com Hall (2003, p. 196), o objeto de tais práticas é composto de significados e mensagens sob a forma de signos-veículo de um tipo específico, organizado, como qualquer forma de comunicação ou linguagem pela operação de códigos dentro da corrente sintagmática de um discurso. Mas é sobre a forma discursiva que a circulação do produto se realiza, bem como sua distribuição para diferentes audiências.

No momento em que o discurso é traduzido e transformado em práticas sociais e cotidianas, ocorre a reprodução dos códigos e signos inseridos na mensagem. Esse é um momento que caracteriza a diferença entre esse circuito circular e o modelo linear de comunicação. Como cada momento possui sua estrutura e condições de existência, esses podem ser responsáveis pela ruptura ou interrupção do processo, em que o próximo passo depende. 
Para que uma determinada mensagem tenha efeito, satisfazendo uma necessidade ou objetivo, deve ser inicialmente apropriada por um discurso significativo e ser significativamente decodificada. Se nenhum sentido for apreendido não ocorrerá o entendimento e compreensão da mensagem, ou seja, não haverá consumo do discurso, consequentemente, não haverá reprodução. As chamadas distorções ou desentendimentos surgem precisamente da falta de equivalência entre os envolvidos na troca comunicativa. Isso define a "autonomia relativa", mas também a "determinação" da entrada e saída da mensagem em seus momentos discursivos.

O processo de comunicação aqui discutido passa a ser considerado como um mecanismo integrante da construção e reconstituição dos sujeitos, das identidades e dos atores sociais e suas práticas. Se já foi apresentado o conceito de discurso e como esse se torna um discurso hegemônico, e também se já foi debatido sobre o processo de comunicação em um circuito dinâmico e contínuo, nos resta apresentar os caminhos metodológicos percorridos ao longo desse estudo e as análises do material coletado.

\section{Questão de método: a análise retórica}

Ao seguir uma perspectiva pós-moderna crítica para a análise retórica, como defendida por Zarchry (2009), é possível focar em como o poder é retoricamente construído. Dessa forma, considera-se a crítica como componente inerente ao trabalho analítico. Para muitos analistas desse tipo de abordagem, a retórica constrói realidades. Sendo assim, certas ideias e formas de pensar são privilegiadas em detrimento de outras tidas como anormais ou ilógicas. O Poder é "inerente a tais usos privilegiados da linguagem, porque adere à ordem percebida das coisas na sociedade” (ZARCHRY, 2009, p. 75).

Em um primeiro momento, identificamos os discursos publicitários das principais marcas do mercado de tablets como Apple, Samsung, Sony e Motorola. Porém, com o desenvolvimento da pesquisa identificamos que outras marcas poderiam enriquecer nosso corpus. Dessa forma, incluímos enunciados publicitários das marcas Toshiba e Dell. Ainda levamos em consideração na primeira etapa do estudo as marcas tidas como "piratas" como, por exemplo, a iRobot com o seu 
aPad. Considerando que algumas dessas marcas possuem mais de um tipo ou geração de tablet e, consequentemente, publicidades específicas para cada um, como é o caso da Apple com o iPad e iPad2, coletamos inicialmente 27 vídeos publicitários presentes no Youtube e nos sites oficiais de cada uma dessas marcas.

Algumas etapas foram assumidas na realização desse estudo partindo da sequência básica de atividades para a condução da análise retórica apresentada por Zachry (2009). No entanto, como o próprio autor afirma, essas etapas não são seguidas sequencialmente em todas as ocasiões. Esse é um processo dinâmico que, em determinada etapa, pode ser necessária a realização de outra etapa simultânea, como ilustrado na Figura 3.

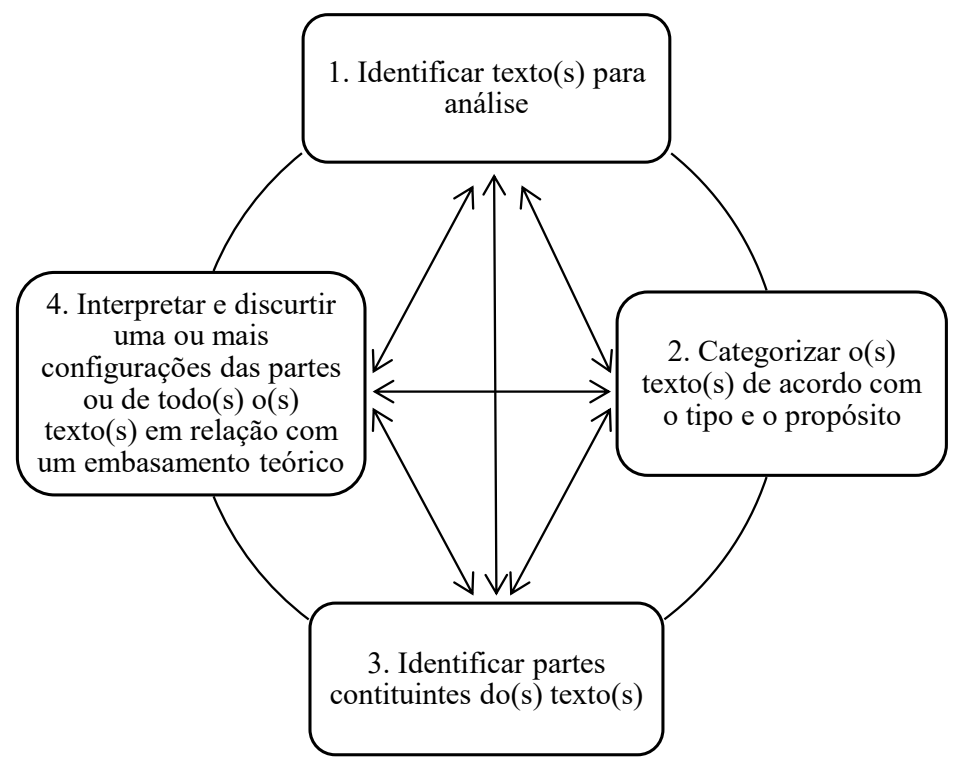

Figura 3: Sequência básica de atividades para realização de análise retórica (ZARCHY, 2009).

Após a coleta, transcrevemos os enunciados de cada vídeo procurando categorizá-los de acordo com seus propósitos. Nesse caso, todos seguem o propósito publicitário de cativar e persuadir os indivíduos a consumir ou desenvolver o consumo dessa inovação tecnológica. Durante a transcrição, consideramos 13 dos 27 iniciais como relevantes para nosso objetivo. Como na Figura 3, buscamos na etapa seguinte 
identificar as partes constituintes dos textos e, em seguida, interpretar e explanar sobre as configurações dessas com base nas assumpções teóricas sobre discurso e relações de poder.

\section{Discurso, poder e dromoaptidão na retórica dos tablets}

Nesta seção trazemos alguns recortes de discursos publicitários dos tablets das marcas Apple, Motorola, Toshiba, Samsung e Dell, os quais possibilitaram a realização da Análise Retórica com base em categorias apresentadas nas primeiras seções desse artigo, a saber, articulação, conceitos, objetos, discurso, hegemonia e poder. Não abandonamos, porém, elementos teóricos pertencentes à própria abordagem retórica como o ethos, o pathos e o logos (ZARCHRY, 2009; LEACH, 2002).

O ethos representa a forma de argumentação persuasiva embasada no caráter e credibilidade do autor do enunciado. O pathos é a forma de persuasão que apela para a emoção, esse tipo é muito comum em textos de publicidade. Por último, o logos se refere à lógica ou uso de argumentos racionais na prática persuasiva. A manipulação ou articulação desses três elementos representam formas de exercício de poder na produção e transmissão de discursos. Os mesmo podem se apresentar com diferentes intensidades em cada contexto. Com o objetivo de preservar os sentidos de cada texto e seus elementos, mantemos os mesmos no idioma em que foram acessados, o inglês.

Os tablets modificaram diferentes práticas cotidianas da sociedade contemporânea, porém a maior parte da população mundial, ou seja, aquela que necessita de mudanças emergenciais na sua realidade socioeconômica e em suas condições de sobrevivência, não possuem poder de acesso a esse tipo de tecnologia e talvez essa não seja uma necessidade de vital importância. Neste sentido, os discursos em torno dos tablets representam parte significante do discurso hegemônico das tecnologias digitais móveis (dentre Smartphones, Google Glass e Apple Watch) que configuram e transformam a realidade social, assim como suas experiências cotidianas em um tipo de sociedade informacional.

A partir da análise dos enunciados emitidos pelos sujeitos que compõem a cadeia de equivalência dominante (Apple, Motorola, Toshiba, Samsung e Dell) foi possível identificar vários conceitos que são articulados na formação dos tablets enquanto objeto discursivo (Figura 4). 


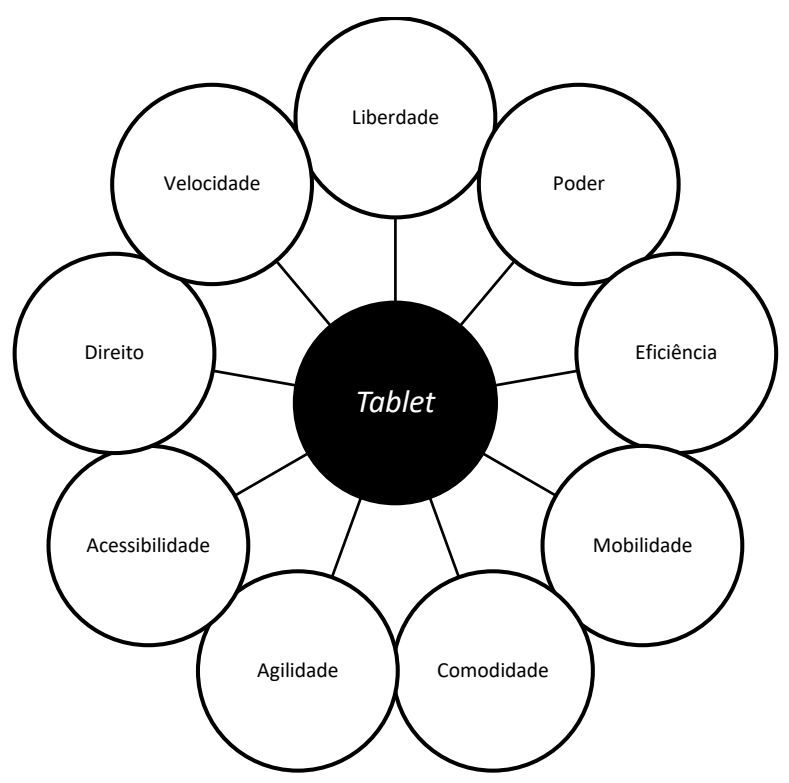

Figura 4: Conceitos e Formação do Objeto Discursivo (os autores).

Após as primeiras análises é possível perceber que os textos selecionados apelam constantemente para as emoções (pathos) e a razão (logos). Como exemplo, podemos apresentar dois enunciados do Xoom, da Motorola: "The tablet to create a better world" e "Is time to live a free life" ; e do FOLIO 100, da Toshiba: "Your life in your hands" e "Can't live without". O apelo aos argumentos referentes à credibilidade do autor, ou seja, ao ethos, é mais evidente nos discursos das grandes marcas como a Apple.

Em diversos enunciados publicitários foi possível identificar a utilização de sentidos de poder. Aparecendo, explicita ou implicitamente, no Xoom, da Motorola: "Empower the People"s; no iPad, da Apple: "...is crazy powerful"; no Galaxy, da Samsung: “...more possibilities on the go"10; e no Streak, da Dell: "The power to do more"11.

\footnotetext{
${ }^{4} 0$ tablet para criar um mundo melhor

${ }^{5}$ É hora de viver uma vida livre

${ }^{6}$ Sua vida nas suas mãos

${ }^{7}$ Não dá pra viver sem

${ }^{8}$ Empodera as pessoas

9 ... é loucamente poderoso

${ }^{10}$... mais possibilidades em movimento

${ }^{11} \mathrm{O}$ poder de fazer mais
} 
Percebe-se aqui que o elemento poder está articulado de formas distintas nos discursos apresentados. De um lado é referido a um poder de emancipação e libertação, por outro, a um poder de acesso a conhecimento e informação, assim como entendimento de realidades e visão de mundos distintos. A forma de identidade construída por esses discursos não são apenas identidades como consumidores de um determinado artefato tecnológico, mas, sim, uma identidade política que posiciona os sujeitos enquanto membros de determinado grupo e reprodutores de seus discursos.

Esses discursos constroem relações de poder inscritas em posições de sujeitos como dromoaptos, que possuem domínio sobre os códigos técnicos e velocidade para acompanhar a aceleração dos avanços e transformações tecnológicas dessa sociedade informacional. No entanto, ao reforçar essas posições de dromoaptos e hegemonizar os discursos dos tablets, relações de exclusão e desigualdades são potencializadas na constituição de outra posição de sujeito, os dromoinaptos. Dessa forma, relações de poder circunscritas nos discursos analisados contribuem na construção dessas posições diferenciais e excludentes, constituindo cadeias de diferença.

Nesse sentido, os dromoinaptos passam a ser vistos como atrasados frente ao avanço e progresso tecnológico dominante (Figura 5). Aqueles que não acompanham tais transformações passam a ser excluídos e marginalizados dessa sociedade da informação. $\mathrm{O}$ dromoapto passa a ter mais poder, reproduzindo e expandindo o discurso hegemônico por meio da constituição de cadeias de equivalências entre diferentes sujeitos, que passam a influenciar a forma como a realidade é pensada e as práticas realizadas.

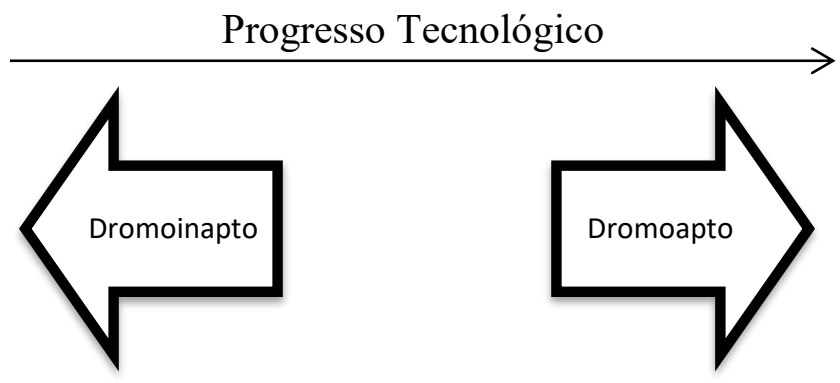

Figura 5: Exclusão Tecnológica (os autores). 
Passamos a analisar agora outros dois recortes discursivos, um referente ao iPad, da Apple, "That's no right way or wrong way"12, e outro do Galaxy, da Samsung, "more possibilities on the go"13. Percebemos que em ambos os ${ }^{9}$ casos, há a presença de um elemento com significado de "liberdade" que concede a possibilidade de fazer qualquer coisa. Assim como no caso discutido anteriormente, esse elemento está sendo apropriado por esses discursos, mas talvez possamos afirmar que seja pertencente à esfera ou campo da ética e da moral, em que existe uma diferenciação entre o certo e o errado, assim como o que pode e o que não pode ser feito, ou seja, estando relacionado a códigos morais e éticos de uma sociedade ou sujeitos coletivos.

O discurso no campo ético se apresenta como discurso primeiro, ou seja, anterior ao discurso publicitário aqui tratado. Sendo assim, essa liberdade representa uma liberdade ilusória com outro sentido, diferente daquele da moral ou da ética, ou seja, o sentido de liberdade entre certo e errado aqui está relacionado às possibilidades de soluções e entretenimento que o artefato concede, assim como a liberdade do próprio consumidor personalizar seu tablet. Nesse caso, elementos éticos e morais são articulados em determinado momento de modo a deslocar seu sentido e significado para outro ponto nodal do campo discursivo. Isso é possível através dos usos de poderes daqueles dromoaptos que influenciam nos deslocamentos desses significados.

Voltamos a análise para outros três recortes dos discursos publicitários referentes ao tablet Xoom, da Motorola, os quais são: "I want software designed for a tablet"14, "I want to know my tablet won't be obsolete overnight"15 " "I want my tablet to be as fast as my PC"16. Um primeiro aspecto aqui é que a Motorola procura se posicionar e se reconhecer como sendo diferente dos outros, ou seja, ela se identifica como um tipo de fabricante por meio do reconhecimento de quem são os outros. A empresa demonstra essas diferenças por meio das características técnicas e/ou materiais que essa possui e outras marcas não. Com base na abordagem retórica podemos identificar nesses textos um apelo maior à persuasão por meio de argumentos racionais (logos).

\footnotetext{
${ }^{12}$ Não existe maneira certa ou errada

${ }^{13}$ Mais possibilidades em movimento

${ }^{14}$ Quero software projetado para um tablet

${ }^{15}$ Quero saber se o meu tablet não ficará obsoleto durante a noite

${ }^{16}$ Quero meu tablet tão rápido quanto meu PC
} 
Quando afirmamos que ela, nos referindo a empresa Motorola, se posiciona pela oposição e diferenciação em relação aos outros, incluímos os sujeitos que fazem parte da realidade da mesma e, dessa forma, reproduzem discursos quanto as suas características técnicas. Talvez uma diferenciação seja feita a empresa Apple por meio do recorte "I want to know my tablet won't be obsolete overnight"17, o qual pode estar se referindo ao curto espaço de tempo entre os lançamentos do iPad e do $i P a d 2$.

De acordo com Pêcheux (2002), somos todos sujeitos pragmáticos que possuímos uma intensa necessidade de homogeneidade lógica, dessa forma estamos sempre nos articulando em um processo de escolha entre $x$ ou $y$. Podemos entender esse processo como escolhas entre uma posição ou outra, dentro de determinado campo de discursividade. Apesar de se diferenciarem dentro do mercado enquanto concorrentes, essas marcas compõem cadeias de equivalência. Os discursos das marcas concorrentes no mercado de tablets, tanto originais quanto "piratas", contribuem para o fortalecimento de um discurso hegemônico em que mesmo instituições religiosas, antes vistas como conservadoras, estão desenvolvendo práticas alinhadas ao discurso dessa tecnologia, como, por exemplo, o confessionário virtual. Como defendido por Foucault (1998), o poder não está conectado a um sujeito, mas, sim, a uma rede complexa de inúmeras posições e jogos de relações desiguais.

\section{Considerações sobre a construção do tablet enquanto discurso}

O processo de dominação de uma cultura elitista ou erudita sobre uma cultura popular ou vulgarizada não ocorre mais como um processo de imposição unicamente de poder de uma sobre a outra. Pelo menos não de uma forma explícita, sentida e percebida por aqueles que são dominados. Ocorre agora uma apropriação de interesses, fatores e aspectos que também são reconhecidos nas classes subalternas ou populares, de modo que haja uma hegemonia presente na cultura e no social, mas que essa não esteja estável, e sim em constante movimento e dialética de apropriação de sentidos e signos que possam ser utilizados para geração de atratividade. Existe uma sobreposição de novas ordens sobre as tradicionais.

As análises desenvolvidas nesse estudo sugerem que as argumentações utilizadas nos discursos publicitários selecionados apelam exten-

\footnotetext{
${ }^{17}$ Quero saber se o meu tablet não ficará obsoleto durante a noite
} 
sivamente para um logos e um pathos em diversos momentos contraditórios e vazios. Mais do que isso, constituem cadeias de equivalências entre os sujeitos dessa sociedade informacional produzindo posições entre dromoaptos e dromoinaptos. Relações essas de desigualdades de poder, onde as formas de pensar (mediadas pelos tablets) são privilegiadas frente a outras consideradas obsoletas.

Uma das limitações desse estudo foi ter dado foco unicamente aos discursos publicitários dessas organizações. Estudos futuros podem avançar nesse sentido ao desenvolver uma análise profunda sobre os impactos reais desses dispositivos ou mecanismos de persuasão nos consumidores de tablets, identificando, dessa forma, como as práticas de consumo e uso dessa tecnologia reproduz os discursos das organizações.

\section{REFERÊNCIAS}

BARBERO, Jesús-Martin. Dos meios as mediações: comunicação, cultura e hegemonia. $2^{\text {a }}$ ed. Rio de Janeiro: Editora da UFRJ, 2003.

BRANDÃO, Helena Hathsue Nagamine. Introdução à análise do discurso. 6a ed. Campinas: Editora da UNICAMP, 1997.

CARVALHO, Nelly de. Publicidade: A linguagem da sedução. São Paulo: Ática, 1996.

CHALABY, Jean. Beyond the prison-house of language: discourse as a sociological concept. British Journal of Sociology, Vol. 47 No. 4, 1996, p. 684-98.

CLEGG, Stewart R. Frameworks of power. London: Sage, 1989.

EMARKETERS. The Global Media Intelligence Report (Latin America). Starcom MediaVest Group, 2015.

FOUCAULT, Michel. Discipline and punish: The birth ofthe prison. London: Penguin, 1979.

FOUCAULT, Michel. The will to knowledge: the history of sexuality. Vol. 1. London: Penguin, 1998.

HALL, Stuart. Foucault: power, knowledge and discourse. In: WETHERELL, Margaret; TAYLOR, Stephanie; YATES, Simeon J. (Ed(s)). Discourse theory and practice: a reader. London: Sage, 2001, p. 72-81. 
HALL, Stuart Da Diáspora: identidades e mediações culturais. Brasília: Editora UFMG, 2003.

HARDY, Cynthia; PHILLIPS, Nelson. No joking matter: Discursive struggle in the Canadian refugee system. Organization Studies, 20 (1), 1999, p. 1-24.

HARDY, Cynthia; PHILLIPS, Nelson. Discourse and Power. In: GRANT, David; HARDY, Cynthia; OSWICK, Cliff; PUTNAM, Linda (Ed(s)). The SAGE Handbook of Organizational Discourse. Thousand Oaks, CA: Sage Publications, 2004, p. 299-316.

HERACLEOUS, Loizos. Interpretivist approaches to organizational discourse. In: Grant, David; HARDY, Cynthia; OSWICK, Cliff; PUTNAM, Linda (Ed(s)). The SAGE Handbook of Organizational Discourse. Thousand Oaks, CA: Sage Publications, p. 175-192, 2004.

JORGENSEN, Marienne; PHILLIPS, Louise. Discourse Analysis as Theory and Method. London: Sage, 2002.

LACLAU, Ernesto; MOUFFE, Chantal. Hegemony and Socialist Strategy: Towards a Radical Democratic Politics. 2a ed. London \& New York: Verso, 2001.

LEACH, Joan. Análise retórica. In: BAUER, Martin W.; GASKELL, George. Pesquisa Qualitativa com Texto, Imagem e Som. Petrópolis, RJ: Editora Vozes, 2004, p. 293-318.

LIMA, Luciana. Dilma sanciona lei que isenta de impostos tablets produzidos no Brasil. Agência Brasil. 2011. Disponível em: http://agenciabrasil.ebc.com.br/noticia/2011-10-11/dilma-sanciona-lei-que-isenta-de-impostos-tablets-produzidos-no-brasil. Acesso em: 05 de janeiro de 2012.

PÊCHEUX, Michel. O discurso: estrutura ou acontecimento? Tradução de Eni P. Orlandi. (3a ed.). Campinas, SP: Pontes, 2002.

PUTNAM, Linda; FAIRHURST, Gail. Discourse analysis in organizations: Issues and concerns. In: JABLIN, Fredric M.; PUTNAM, Linda (Ed(s)). The new handbook of organizational communication: Advances in theory, research and methods. Newbury Park, CA: Sage, p. 235-68, 2001, p. 235-268.

TRIVINHO, Eugênio. A Dromocracia Cibercultural: lógica da vida humana na civilização mediática avançada. São Paulo: Paulus, 2007.

ZACHRY, Mark. Rethoric Analysis. In: BARGIELA-CHIAPPINI, Francesca. The Handbook of Business Discourse. Edinburgh: Edinburgh University Press, 2009, p. 68-79. 